\title{
Serum prostate-specific antigen value adjusted for non-cancerous prostate tissue volume in patients undergoing radical prostatectomy: a new predictor of biochemical recurrence in localized or locally advanced prostate cancer
}

\author{
Ja Hyeon $\mathrm{Ku}^{1}$, Kyung Chul Moon ${ }^{2}$, Sung Yong Cho ${ }^{1}$, Cheol Kwak ${ }^{1}$ and Hyeon Hoe Kim ${ }^{1}$
}

The aim of this study was to investigate the significance of serum prostate-specific antigen (PSA) value adjusted for total tumor volume (PSA/tumor volume) and serum PSA value adjusted for non-cancerous prostate tissue volume (NCPV) (PSA/NCPV) as a predictor of pathological findings and clinical outcome after radical prostatectomy. Clinical and pathological data of 407 patients (median age: 66.5 years; range: 41.8-85.7 years) were reviewed retrospectively. The median follow-up period was 18.1 months (range: $1.0-$

107.8 months). Biochemical recurrence was defined as detectable PSA levels (greater than $0.2 \mathrm{ng} \mathrm{ml}^{-1}$ ) and the time of biochemical recurrence was taken to be the first time PSA became detectable. In the multivariate model, PSA/NCPV was an independent predictor of extracapsular extension and positive surgical margin $(P<0.05)$, but PSA/tumor volume was not. Kaplan-Meier curves revealed that PSA/NCPV correlated with biochemical recurrence-free survival $(P<0.001$; log-rank test) but $P S A / t u m o r$ volume did not $(P=0.275$; log-rank test). PSA/NCPV was also a significant independent prognostic factor for biochemical recurrence-free survival on multivariate Cox proportional hazard analysis $(P=0.004$, relative risk $=2.42)$. Our findings suggest that PSA/NCPV is associated independently with extracapsular extension and surgical margin status and may be an independent prognostic variable of PSA recurrence after radical prostatectomy.

Asian Journal of Andrology (2011) 13, 248-253; doi:10.1038/aja.2010.152; published online 22 November 2010

Keywords: prostatectomy; prostatic neoplasm; PSA; treatment outcome; tumor volume

\section{INTRODUCTION}

Treatment goals of prostate cancer are to potentially cure the disease, prolong biochemical recurrence-free or metastasis-free survival, and improve quality of life. The decision to use adjuvant therapeutic approaches is largely based on prognostic parameters that are known to independently predict tumor-free survival after radical prostatectomy. Some highly predictive prognostic parameters include histopathological feature of the cancer in radical prostatectomy specimens such as Gleason score, extraprostatic extension, positive surgical margin and tumor volume. ${ }^{1}$ Other clinical factors such as prostate-specific antigen (PSA) levels and PSA half-life have also been shown to correlate with treatment failure. ${ }^{2}$ However, there are limitations and no single method allows accurate estimation of the recurrence risk in an individual.

While PSA level correlated strongly with tumor stage, its ability to predict pathological stage for individuals is limited. ${ }^{3}$ This may be due to the presence of benign prostatic hyperplasia $(\mathrm{BPH})$ in the cancerous prostate, which may perturb the direct relationship between tumor volume and serum PSA value. ${ }^{4}$ However, little attention has been paid to the relationships between PSA, tumor volume and non-cancerous prostate tissue volume (NCPV) when considering the adverse effect of $\mathrm{BPH}$ on serum PSA values. These considerations led us to investigate the significance of serum PSA value adjusted for total tumor volume and serum PSA value adjusted for NCPV as predictors of pathological findings and clinical outcome after radical prostatectomy.

Of the patients undergoing radical prostatectomy, 20-50\% will suffer biochemical recurrence. ${ }^{5}$ Prediction of biochemical recurrence after radical prostatectomy is imperative in counseling with patients on adjuvant therapy and prognosis. Therefore, the discovery of a new predictor of recurrence that strongly and independently predicts prostate cancer outcomes could provide complementary information, and aid patients and physicians in clinical decision making. In the present study, serum PSA value adjusted for NCPV provides significant prognostic information in addition to currently used parameters in patients undergoing radical prostatectomy.

\section{METHODS}

Patient population

Approval of the study was obtained from the Institutional Review Board of Seoul National University Hospital. Between 1996 and

${ }^{1}$ Department of Urology, Seoul National University College of Medicine, Seoul 110-744, Korea and ${ }^{2}$ Department of Pathology, Seoul National University College of Medicine, Seoul 110-744, Korea 
2005, 429 radical retropubic prostatectomies for the treatment of prostate cancer were performed at our single institution. The clinical and pathological data of the patients were obtained from our surgical database and reviewed retrospectively. Patients with positive lymph nodes and patients who had received neoadjuvant or immediate adjuvant androgen ablation or radiotherapy were excluded from the study. In total, 407 patients were included in the study. The median age at surgery was 66.5 years (range: $41.8-85.7$ years). The median preoperative PSA level was $8.6 \mathrm{ng} \mathrm{ml}^{-1}$ (range: $0.7-142.0 \mathrm{ng} \mathrm{ml}^{-1}$ ). None of the patients had evidence of nodal disease or distant metastasis on both either contrast-enhanced computed tomography or bone scans.

\section{Histological analysis}

The presence of carcinoma in needle biopsy tissue was assessed by a single pathologist (KCM). Gleason primary and secondary grades with sum scores were assigned and the number of core biopsy specimens containing carcinoma was quantified. The radical prostatectomy specimens were handled and processed in a standard manner, where all prostatic tissue was embedded as previously described. ${ }^{6}$ The presence of extracapsular extension, seminal vesicle invasion, positive surgical margin and histological grade were also recorded. Total tumor volume and the tumor volume of each cancer focus were calculated by using the formula, $0.4 \times$ length $\times$ width $\times$ cross-section thickness, i.e., number of cross sections $\times$ section thickness. ${ }^{7} \mathrm{NCPV}$ was determined by the formula: $\mathrm{NCPV}=$ measured prostate volume-calculated total tumor volume. All specimens were scored according to the Gleason grading system. The pathological stages were recorded on the basis of the 2002 tumor-node metastasis classification and a positive surgical margin was defined as the presence of cancer cells in the inked surface of the prostate specimen.

\section{Follow-up}

Follow-up information was collected from the medical records. All patients were followed up by measuring their PSA levels every 3 months. The median follow-up period was 18.1 months (range: 1.0-107.8 months). Biochemical recurrence was defined as detectable PSA levels (greater than $0.2 \mathrm{ng} \mathrm{ml}^{-1}$ ) and the time of biochemical recurrence was taken to be the first time PSA became detectable.

\section{Statistical analysis}

Pearson correlation coefficients for the relationships between PSA, tumor volume, NCPV, PSA/tumor volume and PSA/NCPV were generated. To identify the factors that could predict pathological findings, odds ratios (ORs) and $P$ values for trends were estimated by univariate and multivariate logistic regression analyses. Several variables were used for these analyses, namely, age at surgery, body mass index, serum PSA level, number of positive biopsy cores, biopsy Gleason score, clinical stage, surgical Gleason score, tumor volume, PSA/tumor volume and PSA/NCPV. Only variables that had a $P$ value less than 0.05 upon univariate analysis were included in the multivariate model.

The Kaplan-Meier method was used to assess the biochemical recurrence-free survival of the patients stratified according to the pathological findings. The differences were tested by using the logrank test. Multivariate Cox proportional hazard analyses were then used to identify prognostic indicators of biochemical recurrence. Only variables that had $P$ value less than 0.05 upon univariate analysis were included in the multivariate model. All $P$ values were two-sided and $P<0.05$ was significant. All statistical analyses were performed by using the SPSS program (SPSS Inc., Chicago, IL, USA).
Table 1 Patient characteristics

\begin{tabular}{|c|c|c|c|}
\hline & No. (\%) & Mean \pm s.e.m. & Median (range) \\
\hline Age (years) & & $65.9 \pm 0.3$ & $66.5(41.8-85.7)$ \\
\hline Body mass index $\left(\mathrm{kg} \mathrm{cm}^{-2}\right)$ & & $23.9 \pm 0.1$ & $24.1(15.3-31.1)$ \\
\hline Serum PSA $\left(n g \mathrm{ml}^{-1}\right)$ & & $13.4 \pm 0.8$ & $8.6(0.7-142.0)$ \\
\hline PSA density $\left(\mathrm{ng} \mathrm{ml} \mathrm{I}^{-1} \mathrm{ml}^{-1}\right)$ & & $0.39 \pm 0.03$ & $0.23(0.01-5.07)$ \\
\hline \multicolumn{4}{|l|}{ Biopsy Gleason score } \\
\hline 4 & $9(2.2 \%)$ & & \\
\hline 5 & $5(1.2 \%)$ & & \\
\hline 6 & $162(39.8 \%)$ & & \\
\hline 7 & $123(30.2 \%)$ & & \\
\hline 8 & $70(17.2 \%)$ & & \\
\hline 9 & $32(7.9 \%)$ & & \\
\hline 10 & $6(1.5 \%)$ & & \\
\hline No. of positive biopsy cores & & $3.8 \pm 0.2$ & $3.0(1.0-12.0)$ \\
\hline \multicolumn{4}{|l|}{ Clinical stage } \\
\hline$<$ ст3а & $329(80.8 \%)$ & & \\
\hline$\geqslant c$ ТТa & $78(19.2 \%)$ & & \\
\hline \multicolumn{4}{|l|}{ Surgical Gleason score } \\
\hline 4 & $2(0.5 \%)$ & & \\
\hline 5 & $4(1.0 \%)$ & & \\
\hline 6 & $97(23.8 \%)$ & & \\
\hline 7 & $236(58.0 \%)$ & & \\
\hline 8 & $31(7.6 \%)$ & & \\
\hline 9 & $35(8.6 \%)$ & & \\
\hline 10 & $2(0.5 \%)$ & & \\
\hline \multicolumn{4}{|l|}{ Surgical margin } \\
\hline Negative & $258(63.4 \%)$ & & \\
\hline Positive & $149(36.6 \%)$ & & \\
\hline \multicolumn{4}{|l|}{ Extracapsular extension } \\
\hline Negative & $273(67.1 \%)$ & & \\
\hline Positive & $134(32.9 \%)$ & & \\
\hline \multicolumn{4}{|l|}{ Seminal vesicle invasion } \\
\hline Negative & $356(87.5 \%)$ & & \\
\hline Positive & $51(12.5 \%)$ & & \\
\hline Tumor volume (ml) & & $7.3 \pm 0.4$ & $3.9(0.2-59.9)$ \\
\hline $\mathrm{NCPV}(\mathrm{ml})$ & & $34.4 \pm 0.8$ & $31.7(2.8-120.7)$ \\
\hline $\begin{array}{l}\text { PSA/tumor volume } \\
\left(\mathrm{ng} \mathrm{ml}^{-1} \mathrm{ml}^{-1}\right)\end{array}$ & & $4.1 \pm 0.3$ & $2.2(0.2-84.8)$ \\
\hline PSA/NCPV $\left(\mathrm{ng} \mathrm{ml}^{-1} \mathrm{ml}^{-1}\right)$ & & $0.67 \pm 0.10$ & $0.25(0.02-31.11)$ \\
\hline
\end{tabular}

Abbreviations: NCPV, non-cancerous prostate tissue volume; PSA, prostate-specific antigen.

\section{RESULTS}

\section{Patient characteristics}

The patient characteristics are listed in Table 1. Of the 407 patients, 329 $(80.8 \%)$ had clinically localized prostate cancer (T1-T2, N0). However, 134 (32.9\%) had extracapsular extension, 51 (12.5\%) had seminal vesicle involvement and $149(36.6 \%)$ had positive surgical margins.

\section{Correlations between serum PSA level, tumor volume and NCPV}

Correlation analysis of the relationships between serum PSA level, tumor volume and NCPV revealed that while correlation between serum PSA level and NCPV was low $(r=-0.179, P<0.001)$, serum PSA level correlated better with tumor volume $(r=0.479, P<0.001)$ and PSA/tumor volume $(r=0.346, P<0.001)$. However, the highest correlation was found between serum PSA and PSA/NCPV $(r=0.626$, $P<0.001)$. Tumor volume also correlated better with PSA/NCPV $(r=0.580, P<0.001)$ than with PSA/tumor volume $(r=-0.267$, $P<0.001)$. The results are shown in Figure 1 . 

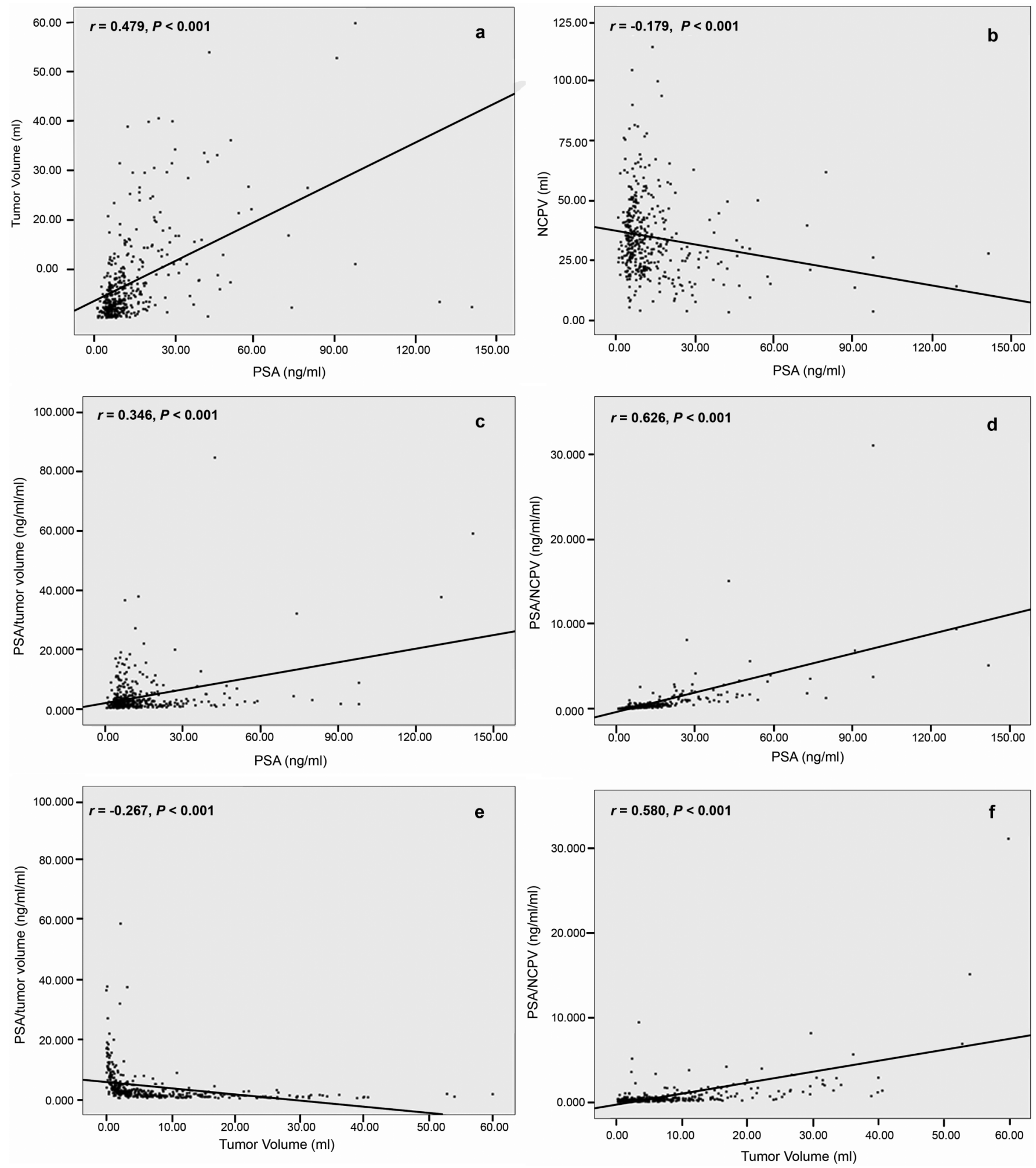

Figure 1 Regression model equations. (a) PSA versus tumor volume ( $r=0.479, P<0.001)$. (b) PSA versus NCPV $(r=-0.179, P<0.001)$. (c) PSA versus PSA/tumor volume ( $r=0.346, P<0.001$ ). (d) PSA versus PSA/NCPV ( $r=0.626, P<0.001)$. (e) Tumor volume versus PSA/tumor volume $(r=-0.267, P<0.001)$. (f) Tumor volume versus PSA/NCPV $(r=0.580, P<0.001)$. NCPV: non-cancerous prostate tissue volume; PSA: prostate-specific antigen.

\section{Prediction of pathological findings}

To identify factors that are predictive of pathological findings, we conducted logistic regression analyses. Univariate logistic regression analysis indicated that serum PSA levels, PSA density, number of positive biopsy cores, biopsy Gleason score, clinical stage, surgical Gleason score, tumor volume, PSA/tumor volume and PSA/NCPV 
Table 2 Univariate and multivariate predictors of pathological findings

\begin{tabular}{|c|c|c|c|c|c|c|}
\hline & Extracapsular ext & & Seminal vesicle invasion & & Positive margin & \\
\hline & $\begin{array}{c}\text { OR }(95 \% \mathrm{Cl}) \\
\text { [Adjusted OR }(95 \% \mathrm{Cl})]\end{array}$ & $\begin{array}{l}\text { P value } \\
\text { [P value] }\end{array}$ & $\begin{array}{c}\text { OR }(95 \% \mathrm{Cl}) \\
\text { [Adjusted OR }(95 \% \mathrm{Cl})]\end{array}$ & $\begin{array}{l}\text { P value } \\
\text { [P value] }\end{array}$ & $\begin{array}{c}\text { OR }(95 \% \mathrm{Cl}) \\
\text { [Adjusted OR }(95 \% \mathrm{Cl})]\end{array}$ & $\begin{array}{l}\text { P value } \\
\text { [P value] }\end{array}$ \\
\hline$<65$ & 1.000 & & 1.000 & & 1.000 & \\
\hline$\geqslant 65$ & $1.087(0.712-1.660)$ & 0.699 & $0.948(0.522-1.721)$ & 0.861 & $0.797(0.529-1.200)$ & 0.277 \\
\hline Body mass ir & $\left.\mathrm{cm}^{-2}\right)$ & & & & & \\
\hline Serum PSA ( & & & & & & \\
\hline$<10$ & 1.000 & & 1.000 & & 1.000 & \\
\hline$\geqslant 10$ & 2.996 (1.953-4.595) & $<0.001$ & $3.929(2.073-7.445)$ & $<0.001$ & 2.059 (1.365-3.105) & 0.001 \\
\hline & [1.334 (0.522-3.406)] & {$[0.547]$} & [0.586 (0.129-2.657)] & [0.488] & {$[1.231(0.492-3.083)]$} & [0.657] \\
\hline PSA density & $\mathrm{ml}^{-1}$ ) & & & & & \\
\hline$<0.25$ & 1.000 & & 1.000 & & 1.000 & \\
\hline$\geqslant 0.25$ & $2.977(1.802-4.917)$ & $<0.001$ & 3.364 (1.565-7.228) & 0.002 & 2.104 (1.299-3.408) & 0.003 \\
\hline & [1.695 (0.815-3.528)] & {$[0.158]$} & [0.971 (0.298-3.171)] & [0.962] & {$[1.980(0.956-4.102)]$} & {$[0.066]$} \\
\hline Biopsy Gleas & & & & & & \\
\hline$\leqslant 6$ & 1.000 & & 1.000 & & 1.000 & \\
\hline 7 & $2.537(1.479-4.353)$ & 0.001 & $4.400(1.540-12.574)$ & 0.006 & $2.198(1.331-3.629)$ & 0.002 \\
\hline & [0.855 (0.378-1.935)] & {$[0.706]$} & [1.357 (0.332-5.551)] & [0.671] & [1.779 (0.774-4.093)] & [0.175] \\
\hline$\geqslant 8$ & $5.342(3.084-9.255)$ & $<0.001$ & $14.014(5.239-37.486)$ & $<0.001$ & 2.235 (1.329-3.759) & 0.002 \\
\hline & [0.699 (0.265-1.845)] & {$[0.470]$} & [1.425 (0.296-6.872)] & [0.659] & {$[1.280(0.479-3.419)]$} & [0.622] \\
\hline Clinical stage & & & & & & \\
\hline$<$ стЗа & 1.000 & & 1.000 & & 1.000 & \\
\hline$\geqslant$ сТЗа & $2.147(1.290-3.573)$ & 0.003 & 3.687 (1.971-6.900) & $<0.001$ & $2.861(1.721-4.756)$ & $<0.001$ \\
\hline & {$[1.463(0.638-3.356)]$} & [0.369] & [2.164 (0.694-6.744)] & [0.183] & [2.824 (1.244-6.408)] & [0.013] \\
\hline Surgical Glea & & & & & & \\
\hline & {$[0.940(0.365-2.419)]$} & {$[0.897]$} & {$[2.941(0.560-15.453)]$} & [0.203] & {$[1.056(0.401-2.782)]$} & [0.912] \\
\hline PSA/tumor ve & $\mathrm{gl}^{-1} \mathrm{ml}^{-1}$ ) & & & & & \\
\hline$<1.5$ & 1.000 & & 1.000 & & 1.000 & \\
\hline $1.5-2.9$ & $0.748(0.457-1.225)$ & 0.249 & $0.412(0.210-0.809)$ & 0.010 & $0.732(0.448-1.196)$ & 0.213 \\
\hline & {$[0.825(0.361-1.885)]$} & [0.648] & [0.515 (0.156-1.698)] & {$[0.276]$} & [0.692 (0.318-1.504)] & [0.352] \\
\hline & & & & & [0.710 (0.304-1.658)] & [0.492] \\
\hline$\geqslant 3$ & $0.373(0.220-0.632)$ & $<0.001$ & $0.073(0.022-0.244)$ & $<0.001$ & $0.562(0.343-0.919)$ & 0.022 \\
\hline & {$[0.509(0.187-1.385)]$} & {$[0.186]$} & [0.196 (0.031-1.225)] & {$[0.081]$} & {$[1.310(0.487-4.523)]$} & [0.593] \\
\hline PSA/NCPV ( $r$ & $\left.\mathrm{nl}^{-1}\right)$ & & & & & \\
\hline$<0.2$ & 1.000 & & 1.000 & & 1.000 & \\
\hline $0.2-0.39$ & $1.709(0.951-3.068)$ & 0.073 & $2.496(0.813-7.661)$ & 0.110 & 3.437 (1.970-5.996) & $<0.001$ \\
\hline & {$[1.255(0.472-3.338)]$} & [0.649] & {$[1.205(0.207-7.004)]$} & {$[0.836]$} & [4.132 (1.592-10.728)] & {$[0.004]$} \\
\hline$\geqslant 0.4$ & $5.585(3.276-9.521)$ & $<0.001$ & $10.561(4.015-27.783)$ & $<0.001$ & $5.121(3.006-8.724)$ & $<0.001$ \\
\hline & [3.593 (1.025-12.602)] & {$[0.046]$} & [2.864 (0.383-21.407)] & {$[0.305]$} & [8.948 (2.444-32.764)] & {$[0.001]$} \\
\hline
\end{tabular}

Abbreviations: $\mathrm{Cl}$, confidence interval; OR, odds ratio; PSA, prostate-specific antigen; NCPV, non-cancerous prostate tissue volume.

were all possible risk factors for extracapsular extension, seminal vesicle invasion and surgical positive margin. In the multivariate model, surgical Gleason score and PSA/NCPV were the only independent predictors of extracapsular extension: a surgical Gleason score $\geqslant 8$ was associated with a 6.7-fold higher chance of extracapsular extension than a surgical Gleason score $\leqslant 6$ (OR: 6.672; 95\% confidence interval (CI): $1.823-24.419 ; P=0.004)$, while a PSA/NCPV value of $\geqslant 0.4$ was associated with a 3.6-fold higher risk of extracapsular extension than a PSA/NCPV value of $<0.2$ (OR: 3.593 ; 95\% CI: $1.025-12.602 ; P=0.046$ ).

The multivariate analysis used in this study also showed that the OR (with a 95\% CI representing the space between the high and low quartiles) for seminal vesicle invasion was increased for one factor only, namely, surgical Gleason score: a surgical Gleason score $\geqslant 8$ was associated with a 17.1-fold higher risk of seminal vesicle invasion 
than a surgical Gleason score $\leqslant 6$ (OR: 17.076; 95\% CI: 1.328-219.611; $P=0.029)$.

Moreover, the multivariate logistic model indicated that PSA density, clinical stage and PSA/NCPV were dependent risk factors for a positive surgical margin. Patients with PSA density $\geqslant 0.25$ had a 2.9fold greater risk of having a positive margin (OR: 2.934; $95 \%$ CI: $1.070-8.048, P=0.037)$. A clinical stage of $\geqslant \mathrm{cT} 3$ a was associated with a 2.8-fold higher likelihood of positive surgical margin (OR: 2.824; 95\% CI: $1.244-6.408 ; P=0.013)$. Compared to a PSA/NCPV value of $<0.2$, a PSA/NCPV value of $0.2-0.39$ was associated with a 4.1 -fold higher risk (OR: 4.132; 95\% CI: $1.592-10.728 ; P=0.004$ ), while a PSA/ NCPV value of $\geqslant 0.4$ (OR: 8.948 ; 95\% CI: $2.444-32.764 ; P=0.001$ ) was associated with a 8.9-fold higher risk. The results are shown in Table 2.

\section{Biochemical recurrence after radical prostatectomy}

At the median follow-up period of 18.1 months, biochemical recurrence was observed in 100 patients $(24.6 \%)$. The median time to biochemical recurrence was 12.0 months (range: 0.5-107.8 months). The 1-, 3- and 5-year biochemical recurrence-free survival rates were $80.0,59.9$ and $52.3 \%$, respectively. Kaplan-Meier curves revealed that surgical Gleason score $(P<0.001$; log-rank test), surgical margin status $(P<0.001$; log-rank test $)$, extracapsular extension $(P<0.001$; log-rank test), seminal vesicle invasion ( $P<0.001$; log-rank test $)$, tumor volume $(P<0.001$; log-rank test $)$ and PSA/NCPV $(P<0.001$; log-rank test $)$ correlated with biochemical recurrence-free survival, whereas PSA/ tumor volume did not correlate with biochemical recurrence-free survival $(P=0.275$; log-rank test $)$.

\section{Multivariate analysis}

Multivariate Cox proportional hazard analysis revealed that surgical Gleason score $(P=0.049$, relative risk $=2.33)$, surgical margin $(P<0.001$, relative risk $=3.10)$, seminal vesicle invasion $(P=0.009$, relative risk $=2.10)$ and PSA/NCPV $(P=0.004$, relative risk $=2.42)$ were significant independent prognostic factors of biochemical recurrence-free survival, whereas tumor volume lost its statistical significance (Table 3).

\section{DISCUSSION}

Patients at a high risk of cancer progression should be identified as soon as possible because some of these patients may benefit from adjuvant therapeutic regimens. This highlights the importance of identifying parameters that can reliably predict the risk of cancer progression in individual patients who have been diagnosed with prostate cancer. While clinical and pathological stage, namely, PSA levels and Gleason score, respectively, are good and well-established prog-

Table 3 Association of pathological findings with biochemical recurrence-free survival on multivariate Cox proportional hazards regression analysis

\begin{tabular}{lcrr}
\hline Variables & HR & 95\% Cl & P value \\
\hline Surgical Gleason score ( $\leqslant 6$ versus 7$)$ & 1.677 & $0.790-3.561$ & 0.179 \\
Surgical Gleason score ( $\leqslant 6$ versus $\geqslant 8)$ & 2.327 & $1.005-5.391$ & 0.049 \\
Surgical margin (negative versus positive) & 3.101 & $1.945-4.944$ & $<0.001$ \\
Extracapsular extension (negative versus positive) & 1.245 & $0.748-2.073$ & 0.399 \\
Seminal vesicle invasion (negative versus positive) & 2.096 & $1.208-3.637$ & 0.009 \\
Tumor volume (<4 ml versus $\geqslant 4$ ml) & 0.760 & $0.464-1.246$ & 0.277 \\
PSA/NCPV (<0.2 versus 0.2-0.39) & 1.112 & $0.580-2.134$ & 0.749 \\
PSA/NCPV $(<0.2$ versus $\geqslant 0.4)$ & 2.424 & $1.322-4.445$ & 0.004 \\
\hline
\end{tabular}

Abbreviations: $\mathrm{Cl}$, confidence interval; $\mathrm{HR}$, hazard ratio; NCPV, non-cancerous prostate tissue volume; PSA, prostate-specific antigen. nosticators, there is a need to develop new tools by which patients can be further stratified with regard to disease status.

At present, there is a great deal of debate about whether tumor volume should be recommended as a prognostic parameter for predicting disease-free survival in patients after radical prostatectomy. Stamey et al. ${ }^{8}$ consider tumor volume to be an independent prognostic parameter that can also be used to differentiate significant from insignificant cancer. In contrast, Epstein et al..$^{9}$ have demonstrated that tumor volume does not provide additional information if the Gleason score and pathological stage are known. We also found in the present study that prostate cancer volume was not a significant predictor of biochemical failure after radical prostatectomy on multivariate analysis.

PSA is produced not only by prostate tumor but also by benign tissue, and its level increases with the size of the prostate. While it has been suggested that the serum PSA level reflects the size of the prostate, serum PSA alone predicts tumor size poorly. ${ }^{10}$ This may be because of $\mathrm{BPH}$, the volume of which can be significant: if a cancerous prostate gland also has $\mathrm{BPH}$, the $\mathrm{BPH}$ may interfere with the direct relationship between tumor volume and serum PSA values. ${ }^{4}$ This is supported by the findings in the present study: while tumor volume correlated reasonably well with serum PSA $(r=0.479, P<0.001)$, there was also a weak inverse correlation between NCPV and serum PSA $(r=-0.179, P<0.001)$.

There is a higher incidence of finding a well-differentiated tumor at prostatectomy in patients with a large prostate, ${ }^{11}$ whereas men with a small prostate tend to have more advanced disease and to be at greater risk of progression after radical prostatectomy. ${ }^{12}$ It has been shown that poorly differentiated cancers tend to produce less PSA per volume of tumor tissue. ${ }^{4}$ Moreover, Hayashi et al. ${ }^{13}$ reported recently that when PSA is adjusted for tumor volume, a low level is an independent predictor of biological failure. These findings suggest that prostate cancers that are associated with lower PSA secretion levels are associated with a higher risk of biochemical failure after surgery; they also suggest that the combination of a large tumor and low serum PSA level may reflect an aggressive phenotype, irrespective of the degree of BPH. However, the current study failed to find that tumor volume, or serum PSA level adjusted for tumor volume, was a significant predictor of PSA recurrence when adding serum PSA level adjusted for NCPV to the Cox proportional model. Furthermore, we observed that serum PSA value adjusted for NCPV was associated independently with extracapsular extension and surgical margin status and was an independent prognostic variable for PSA recurrence after radical prostatectomy. Indeed, radical prostatectomy specimens contain the index tumor (the largest tumor) and smaller satellite tumors. ${ }^{14}$ Noguchi et al. ${ }^{15}$ found that only index tumor volume, but not total tumor volume, was an independent predictor of biochemical recurrence. Wise et al. ${ }^{16}$ also indicated that the importance of the index tumor rather than all tumors in radical prostatectomy specimens to predict prognosis. This would explain why tumor volume or serum PSA level adjusted for tumor volume was not a significant predictor of PSA recurrence in our study.

The influence of BPH on the serum PSA value depends on the volume of both the tumor and the non-cancerous prostatic tissue. We observed a significant inverse relationship between tumor volume and serum PSA value adjusted for tumor volume $(r=-0.267$, $P<0.001)$. This reveals that the serum level of PSA does not increase in a proportional fashion with the volume of prostate cancer; rather, as tumor volume increases, the amount of serum PSA per cubic centimeter of tumor decreases. More interestingly, the present study showed that serum PSA value adjusted for NCPV correlated directly with both PSA $(r=0.626, P<0.001)$ and tumor volume $(r=0.580$, $P<0.001)$. Thus, the amount of serum PSA per cubic centimeter of 

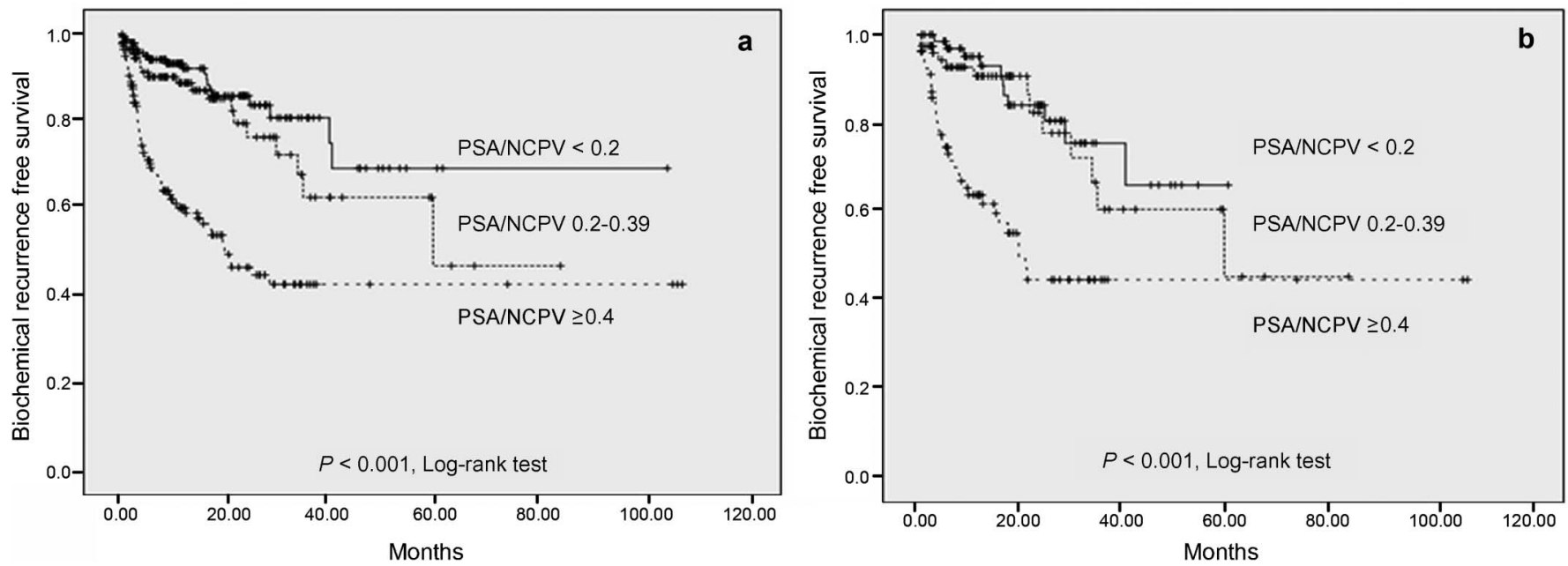

Figure 2 Biochemical recurrence-free survival in patients categorized according to serum prostate-specific antigen value adjusted for non-cancerous prostate tissue volume in total patients (a) and in patients with surgical Gleason score of 7 (b). NCPV: non-cancerous prostate tissue volume; PSA: prostate-specific antigen.

NCPV increases as the tumor volume or serum PSA level increases. These findings suggest that NCPV may contribute to the elevation of serum PSA in patients with large tumor volume.

Regarding PSA density, several investigators have suggested that a greater PSA density could reflect a greater tumor burden, adverse pathological findings and a worse prognosis. ${ }^{17,18}$ However, others have found no additional benefit using this parameter. ${ }^{19,20}$ In our series, PSA density correlated with PSA value adjusted for NCPV ( $r=0549, P<0.001$; data not shown). However, in our multivariate regression analysis, although PSA density was an independent predictor of positive surgical margin, it was not associated with extracapsular extension or seminal vesicle invasion. These findings suggest that PSA value adjusted for NCPV might provide a more accurate measure of cancer aggressiveness since PSA level is related more closely to NCPV than prostate cancer. ${ }^{21}$

In the present study, serum PSA value adjusted for NCPV provides significant prognostic information in patients undergoing radical prostatectomy. In addition, this new predictor may provide complementary information. For example, we found that in patients with surgical Gleason score of 7, serum PSA value adjusted for NCPV correlated with biochemical recurrence-free survival (Figure 2). Therefore, further study with regard to this issue is needed.

\section{AUTHOR CONTRIBUTIONS}

Both Ja Hyeon Ku and Cheol Kwak worked on the concept and design, and drafting of the manuscript; Kyung Chul Moon worked on acquisition of data and critical revision; Sung Yong Cho worked on acquisition of data and statistical analysis; and Hyeon Hoe Kim worked on concept and design, and critical revision.

\section{COMPETING FINANCIAL INTERESTS}

The authors declare no competing financial interests.

1 Kikuchi E, Scardino PT, Wheeler TM, Slawin KM, Ohori M. Is tumor volume an independent prognostic factor in clinically localized prostate cancer? J Urol 2004; 172: $508-11$.

2 Lin GW, Yao XD, Zhang SL, Dai B, Ma CG et al. Prostate-specific antigen half-life: a new predictor of progression-free survival and overall survival in Chinese prostate cancer patients. Asian J Androl 2009; 11: 443-50.
3 Babaian RJ, Camps JL, Frangos DN, Ramirez EI, Tenney DM et al. Monoclonal prostate-specific antigen in untreated prostate cancer. Relationship to clinical stage and grade. Cancer 1991; 67: 2200-6.

4 Partin AW, Carter HB, Chan DW, Epstein Jl, Oesterling JE et al. Prostate specific antigen in the staging of localized prostate cancer: influence of tumor differentiation, tumor volume and benign hyperplasia. J Urol 1990; 143: 747-52.

5 Sandler HM, Eisenberger MA. Assessing and treating patients with increasing prostate specific antigen following radical prostatectomy. J Urol 2007; 178: S20-4.

6 Humphrey PA, Keetch DW, Smith DS, Shepherd DL, Catalona WJ. Prospective characterization of pathological features of prostatic carcinomas detected via serum prostate specific antigen based screening. J Urol 1996; 155: 816-20.

7 Chen ME, Johnston D, Reyes AO, Soto CP, Babaian RJ et al. A streamlined threedimensional volume estimation method accurately classifies prostate tumors by volume. Am J Surg Pathol 2003; 27: 1291-301.

8 Stamey TA, McNeal JE, Yemoto CM, Sigal BM, Johnstone IM. Biological determinants of cancer progression in men with prostate cancer. JAMA 1999; 281: 1385-400.

9 Epstein JI, Carmichael M, Partin AW, Walsh PC. Is tumor volume an independent predictor of progression following radical prostatectomy? A multivariate analysis of 185 clinical stage B adenocarcinoma of the prostate with 5 years of follow-up. J Urol 1993; 149: 1478-81.

10 Babaian RJ, Troncoso P, Steelhammer LC, Lloreta-Trull J, Ramirez EI. Tumor volume and prostate specific antigen: implications for early detection and defining a window of curability. J Urol 1995; 154: 1808-12.

11 Kassouf W, Nakanishi H, Ochiai A, Babaian KN, Troncoso P et al. Effect of prostate volume on tumor grade in patients undergoing radical prostatectomy in the era of extended prostatic biopsies. J Urol 2007; 178: 111-4.

12 Freedland SJ, Isaacs WB, Platz EA, Terris MK, Aronson WJ et al. Prostate size and risk of high-grade, advanced prostate cancer and biochemical progression after radical prostatectomy: a search database study. J Clin Oncol 2005; 23: 7546-54.

13 Hayashi N, Urashima M, Ikemoto I, Kuruma H, Arai Y et al. Prostate-specific antigen adjusted for total prostate tumor volume as a predictor for outcome after radical prostatectomy. Prostate Cancer Prostatic Dis 2007; 10: 60-5.

14 Mouraviev V, Mayes JM, Polascik TJ. Pathologic basis of focal therapy for early-stage prostate cancer. Nat Rev Urol 2009; 6: 205-15.

15 Noguchi M, Stamey TA, McNeal JE, Nolley R. Prognostic factors for multifocal prostate cancer in radical prostatectomy specimens: lack of significance of secondary cancers. J Urol 2003; 170: 459-63.

16 Wise AM, Stamey TA, McNeal JE, Clayton JL. Morphologic and clinical significance of multifocal prostate cancers in radical prostatectomy specimens. Urology 2002; 60: 264-9.

17 Bhayani SB, Bullock AD, Liefu Y, Andriole GL, Kibel AS. Is prostate-specific antigen (PSA) density better than the preoperative PSA level in predicting early biochemical recurrence of prostate cancer after radical prostatectomy? BJU Int 2006; 97: 480-4.

18 Radwan $\mathrm{MH}$, Yan Y, Luly JR, Figenshau RS, Brandes SB et al. Prostate-specific antigen density predicts adverse pathology and increased risk of biochemical failure. Urology 2007; 69: 1121-7.

19 Freedland SJ, Kane CJ, Presti JC Jr, Terris MK, Amling CL et al. Comparison of preoperative prostate specific antigen density and prostate specific antigen for predicting recurrence after radical prostatectomy: results from the search data base. J Urol 2003; 169: 969-73.

20 Brassell SA, Kao TC, Sun L, Moul JW. Prostate-specific antigen versus prostatespecific antigen density as predictor of tumor volume, margin status, pathologic stage, and biochemical recurrence of prostate cancer. Urology 2005; 66: 1229-33.

21 Stamey TA, Caldwell M, McNeal JE, Nolley R, Hemenez M et al. The prostate specific antigen era in the United States is over for prostate cancer: what happened in the last 20 years? J Urol 2004; 172: 1297-301. 